\title{
Eddy Current Loss Control in High Speed PM Starter-Generator
}

\author{
Xiaochen Zhang, He Zhang, Chris Gerada, David Gerada, Jing Li, Zeyuan Xu, Chuan Liu
}

\begin{abstract}
This paper highlights the advancement in high speed generation applications along with describing the state of the art in the machine design technologies enabling such an application uptake. Via the investigating on a $250 \mathrm{~kW}$ high speed PM starter-generator by using the 3-D FEA, the eddy current loss in rotor restrain sleeve, stator end-caps, as well as those in magnets are studied in the view of material and geometry dimensions. Some design arts or dimensions refers to minimize machine eddy current losses going to the minimum are proposed, which are verified by experiments. Both the obtained results and proposed conclusions are have of important significant for high speed machine design or optimization.
\end{abstract} FEA.

Index Terms - Eddy current, Loss, High speed machines, 3-D

\section{INTRODUCTION}

$\mathrm{E}$ LECTRIFICATION of transport affords a great opportunity to address emission 1 and climate change issues. While electrification to date has been mainly concerned with secondary systems, rapidly extending areas are those of the more electric engine and general electrified traction and drives [1][2]. From an aerospace perspective, the emissions predictions due to jet fuels is growing at an alarming rate. It is estimated from ongoing market and research studies that electrification activities in aerospace will comprise an increase to approximately $50 \%$ of more electric aircraft (MEA) activities, in the next 10 years [3].

At the heart of all this effort and push towards electrification is the electrical drive itself. Electric drives constitute the backbone of industrial automation, and their diffusion has been constantly increasing in every field, especially in the transportation industry. In fact, the evergrowing push towards more responsible and sustainable transport is resulting in electrical systems becoming more and more important [4].

Traditionally, generating systems on aircraft and marine applications tend to make use of a field wound synchronous

This work was supported in part by the Ningbo Science \& Technology Beauro, grant number 2014A35007. This work is also supported by the National Natural Science Foundation of China under Grant 51407006, and the Fundamental Research Funds for the Central Universities of China under Grant 2016RC028.

Xiaochen Zhang is with The University of Nottingham, University Park, NG7 2RD UK (e-mail: xiaochen.zhang@nottingham.ac.uk).

He Zhang is with the University of Nottingham Ningbo China, Ningbo Zhejiang, 315100 China (e-mail: he.zhang@nottingham.edu.cn).

Chris Gerada, David Gerada, and Zeyuan Xu are with The University of Nottingham, University Park, NG7 2RD UK (e-mail: Chris.gerarda@nottingham.ac.uk,_David.gerada@nottingham.ac.uk, Zeyuan.xu@nottingham.ac.uk).

Jing Li, and Chuan Liu are with the University of Nottingham Ningbo China, Ningbo Zhejiang, 315100 China (e-mail: Jing.li@nottingham.edu.cn, Chuan.liu@nottingham.edu.cn,). machine (FWSM) with field excitation, a rectifier unit and an automatic voltage regulation (AVR) unit. The main advantage of this technology is its inherent simplicity due to only a small number of components being used and therefore it is considered to be quite a rugged and robust solution. Passive rectification is achieved by simply employing passive diodes [5].

Significant improvements in terms of weight and volume can be achieved by using PM machine technologies. The PM drive being proposed for next generation aero plane power system. The power density performance values of the proposed starter-generator are almost $3 \mathrm{~kW} / \mathrm{kg}$, which goes beyond the current state of the art of electrical generation systems on board [6-8].

As the increase of machine power density on board, more benefits like weight and space reduce could be realized. However, the loss per volume is also larger, which may take more pressure for thermal management and lower machine performance. Beside to design more effective cooling system, make the loss in machine close to its minimum boundary is one important way to ensure machine steady operating[9], especially for those of high speed permanent magnetic (PM) starter-generator for aero planes.

For high speed permanent magnetic starter-generator, its copper loss and iron loss are could be determined by analytical method, whilst the mechanical loss mainly depends on operating speed [10][11]. The control of eddy current loss is one of the effective way to reduce machine total loss, and also to manage loss distribution inside machine [12]. In this paper, a $250 \mathrm{~kW} 24 \mathrm{krpm}$ PM machine is developed as a starter-generator for aero planes, and the design arts to control eddy losses in rotor restrain sleeve, stator end-caps, and magnets are proposed.

\section{DeVElop OF High SPEEd PM StARTER-GENERATOR}

A $250 \mathrm{~kW}$ high speed PM starter-generator is developed for next generation MEA. The electric power system is designed to be able to operate at $\pm 270 \mathrm{~V}$, i.e. the insulation system will be developed and designed for this high voltage characteristics. The studies are performed based on combined analytical and Finite Element Analyses (FEA), which are take the 2-D and 3-D transient electromagnetic field investigation jointly [10].

For the restrict of overwhelm machine volume, the space of the end region inside machine is quite limit, and the flux leakage, either from rotor or end windings, may cause eddy current loss in stator end-caps. However, the traditional analytical methods, which is difficult to accurately calculate the magnetic field leakage and flux saturation, it couldn't take the end leakage effect of magnetic field into 
consideration. With the time step finite element numerical method, though the above magnetic field saturation and the nonlinear effect can be preferably considered, the generator magnetic field influenced by the power system fluctuation still can't be considered[13][14].

Looking at the limitation of the traditional method, the mathematical model is proposed, which not only exactly consider the nonlinear effect of magnetic field saturation and distortion in the generator end region, but also include the control system impacts. By solving the systematical time stepping finite element equation with the multi-regional synergistic coupling numerical method, the reliability of thorny problem for the end leakage magnetic field distribution can be improved.

To simplify the analysis, with the simplified analysis under the basic hypothesis, for the core length region, a 2-D electromagnetic field is used. The electromagnetic quantities can be obtained through the finite element analyzing.

$$
\left\{\begin{array}{l}
\Omega: \frac{\partial}{\partial x}\left(\frac{1}{\mu} \cdot \frac{\partial A_{z}}{\partial x}\right)+\frac{\partial}{\partial y}\left(\frac{1}{\mu} \cdot \frac{\partial A_{Z}}{\partial y}\right)=-J_{Z}+\sigma \frac{d A_{Z}}{d t} \\
\Gamma: A_{Z}=0
\end{array}\right.
$$

where, $\sigma$ is the electric conductivity (in $\mathrm{S} / \mathrm{m}$ ), $\mu$ is the magnetic conductivity (in $\mathrm{H} / \mathrm{m}$ ), $t$ is time (in $\mathrm{s}$ ), $J_{Z}$ is the source current density, $A_{\mathrm{Z}}$ is the magnetic vector potential (in $\mathrm{Wb} / \mathrm{m}$ ) with only $\mathrm{z}$ axial component.

Whilst for machine end region, the 3-D electromagnetic field investigation, which has a similar process to those for the solving process of $2-\mathrm{D}$ case, is performed. The solving region $\Omega$ of 3-D electromagnetic field on end region is divided into the non-eddy current zone $V_{1}$ for components ignoring eddy current like windings and air, and the eddy current zone $V_{2}$ for solid components as endcaps.

The electric vector potential $\boldsymbol{A}$ and magnetic scalar potential $\psi$ are adopted to solve the mathematical model of electromagnetic field on end region of the starter-generator.

In $V_{1}$, including the windings, the stator core:

$$
\left\{\begin{array}{l}
\nabla \times \frac{1}{\sigma} \nabla \times \boldsymbol{A}-\nabla \frac{1}{\sigma} \nabla \cdot \boldsymbol{A}+\frac{\partial \mu(\boldsymbol{A}-\nabla \psi)}{\partial t}+\frac{\partial \mu \boldsymbol{H}_{s}}{\partial t}=0 \\
\nabla \cdot \mu(\boldsymbol{A}-\nabla \psi)=-\nabla \cdot \mu \boldsymbol{H}_{s}
\end{array}\right.
$$

In $V_{2}$, including the magnets, the rotor sleeve, the endcap edge :

$$
\nabla \cdot \mu \nabla \psi=\nabla \cdot \mu \nabla \boldsymbol{H}_{s}
$$

where, $\boldsymbol{H}_{s}=\frac{1}{4 \pi} \int_{\Omega_{s}} \frac{\boldsymbol{J}_{s} \times \boldsymbol{r}}{r^{3}} d \Omega, \Omega_{s}$ is source containing zone, $\boldsymbol{J}_{s}$ is current density of winding source (in $\mathrm{A} / \mathrm{m}^{2}$ ).

The boundary condition is as

$$
\left\{\begin{array}{l}
\left.\frac{\partial \psi}{\partial \boldsymbol{n}}\right|_{S_{1}, S_{2}}=0 \\
\left.\psi\right|_{S_{3}}=\psi_{0}
\end{array} .\right.
$$

When $t=0$, the initial boundary condition is

$$
\left\{\begin{array}{l}
\left.A\right|_{V_{1}}=A_{0}(r, \theta, z) \\
\left.\psi\right|_{\Omega}=\psi_{0}(r, \theta, z)
\end{array},\right.
$$

where, $\boldsymbol{A}_{0}$ is electric vector potential, $\psi_{0}$ is magnetic scalar potential, $\boldsymbol{n}$ is normal direction of surface, $r, \theta$ and $z$ are the space position in cylindrical coordinate, and $r$ in radial direction, $\theta$ in circumferential direction, $z$ in axial direction.

With the proposed method, the process for the calculation process is shown in Fig. 1.

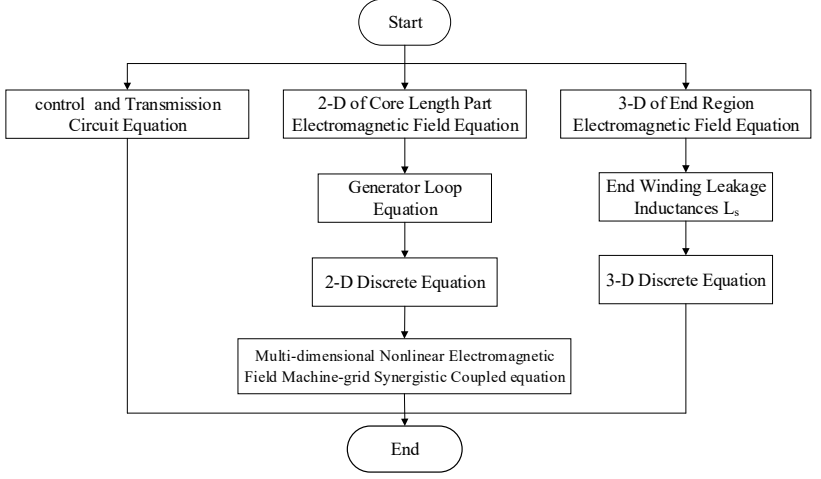

Fig. 1. Flow diagram of the multi-regional nonlinear transient electromagnetic field coupling analyses process.

Based on the above flowchart, the 2-D FEA model on core length segment part and the 3-D finite element calculation model on the end region are respectively established. Based on the principle designed high speed PM starter-generator geometry, and the boundary condition is set up as shown in Fig. 2.

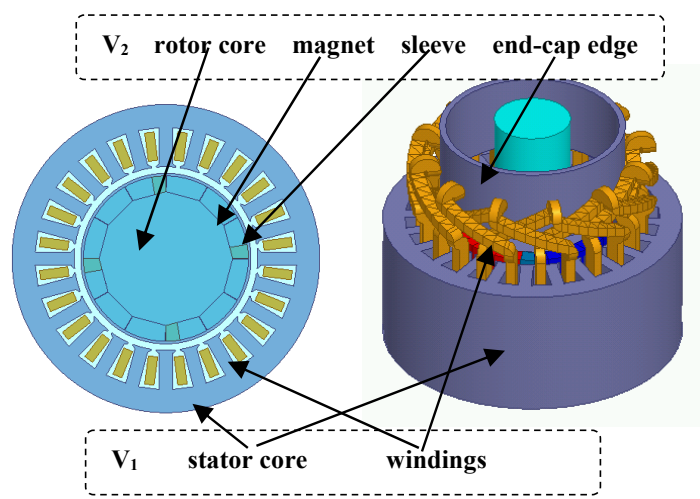

Fig. 2. 2-D and 3-D finite element model.

The high speed PM starter-generator machine is designed with 36 slots, 4 pole. The main parameters are list in Table I. The developed machine has of active weight of $56.67 \mathrm{~kg}$, and the practical weight of prototype, as shown in Fig. 3 , is $79 \mathrm{~kg}$.

The developed prototype is tested on a $150 \mathrm{~kW} 10000 \mathrm{rpm}$ rig, shown as in Fig.3, and the back EMF is measured under different speed. The tested back EMF is $134.35 \mathrm{v}$ at $7000 \mathrm{rpm}$, and the average THD is $0.59 \%$. The designed back EMF is $133 \mathrm{Vac}$ at $7000 \mathrm{rpm}$, and the difference is $+1.12 \%$.

Meanwhile, machine no-load total loss at 10000rpm is tested as $1985.9 \mathrm{~W}$, which is simulated as $1883.2 \mathrm{~W}$. For the copper loss and friction loss are quite small, the calculation of core loss could be verified. 
TABLE I

MAIN PARAMETERS OF THE DEVELOPED HIGH SPEED PM STARTER GENERATOR

\begin{tabular}{cc}
\hline Rated Parameter & Value \\
\hline Rated power/kW & 250 \\
Rated voltage/V & \pm 270 \\
Rated current/A & 382 \\
Starting speed/ rpm & $0-14000$ \\
Generating speed/ rpm & $14000-24000$ \\
Core length/mm & 207 \\
Active weight/ kg & 56.67 \\
\hline
\end{tabular}

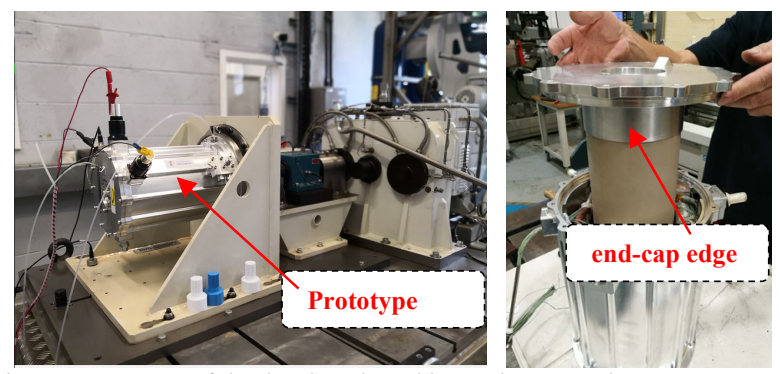

Fig. 3. Prototype of the developed machine and stator end-cap.

\section{THE EDDY CURRENT LOSS IN MACHINE}

\section{A. Rotor Sleeve}

In the original design, the rotor sleeve is designed of carbon fibre with thickness of $4 \mathrm{~mm}$, which has of advantages in strength and loss but bad thermal conductivity. For the thermal limit of glue, rotor and carbon fibre sleeve working temperature is designed below $180{ }^{\circ} \mathrm{C}$. The prototype is cooled by half oil immersion system, in which the armature windings is cooled by coolant directly, but no other cooling measurement for rotor. Therefore, the reduction of rotor sleeve is has of more significance.

By using the 3-D FEA, the eddy current loss in rotor sleeve could be obtained. To investigate the eddy loss in rotor sleeve, other three materials, as stainless, Inconel 725 , Titanium are designed as rotor restrain sleeve. Meanwhile, the effects of thickness of metal sleeve on machine performance are investigated. The obtained machine performance and loss distribution are compared in Table II

TABLE II

MAin PARAMETERS OF THE DEVEloped High SPEEd PM StARTER GENERATOR

\begin{tabular}{lcccccc}
\hline $\begin{array}{l}\text { Performance/sleev } \\
\text { e material }\end{array}$ & $\begin{array}{c}\text { Carbon } \\
\text { fiber }\end{array}$ & $\begin{array}{c}\text { Stainles } \\
\text { s }\end{array}$ & INCONEL 725 & Titanium \\
\hline $\begin{array}{l}\text { Sleeve thickness } \\
\text { /mm }\end{array}$ & 4 & 4 & 4 & 3 & 2 & 4 \\
Conductivity / 10 & 0.0256 & 1.1 & 0.556 & 0.556 & 0.556 & 1.8 \\
S/m & 929 & 929 & 929 & 929 & 929 & 929 \\
Copper loss/W & 3220.6 & 2889.4 & 2892 & 2892 & 2892.4 & 2895.3 \\
$\begin{array}{l}\text { Stator core loss/W } \\
\text { Eddy loss in rotor }\end{array}$ & 4.46 & 3102 & 1721 & 802.3 & 353.1 & 4459.3 \\
sleeve/W & 234 & 200 & 200 & 200 & 200 & 201.2 \\
$\begin{array}{l}\text { Eddy loss in } \\
\text { magnets/W }\end{array}$ & 338 & 338 & 338 & 338 & 338 & 338 \\
$\begin{array}{l}\text { Friction loss/W } \\
\text { Total loss/W }\end{array}$ & 4947.5 & 7679.8 & 6301.4 & 5382.7 & 4933.9 & 9044.2 \\
$\begin{array}{l}\text { Loss per output } \\
\text { W/kW }\end{array}$ & 19.28 & 30.86 & 26.33 & 22.52 & 20.54 & 37.87 \\
\hline
\end{tabular}

From the analyses above, the skin effect thickness of the $1^{\text {st }}$ order flux is $6.1 \mathrm{~mm}$, which means, the reduced harmonics by the metal sleeve is quite limited, and the eddy current loss induced in magnets are almost the same. But for carbon fibre sleeve, without the eddy field in sleeve, the eddy loss in magnets is $21 \%$ higher than those in mantle sleeve rotor.

The eddy loss of sleeve is sensitive with material, and the total loss increase $49 \%$ after the use of stainless sleeve. The heat transmission in rotor is much difficult than that in stator, and the metal sleeve will make it worse. As the decrease of sleeve thickness (INCONEL 725), its eddy loss reduces obvious. As shown in Fig.4.

The use of metal sleeve should also consider the mechanical requests, and a reduced sleeve thickness will benefit its utilization.

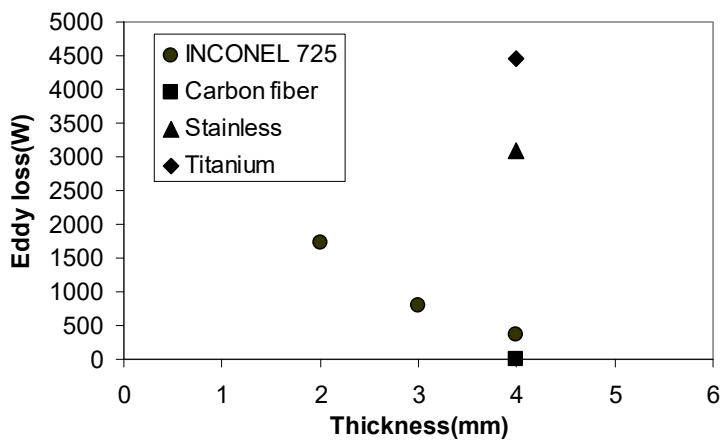

(a)

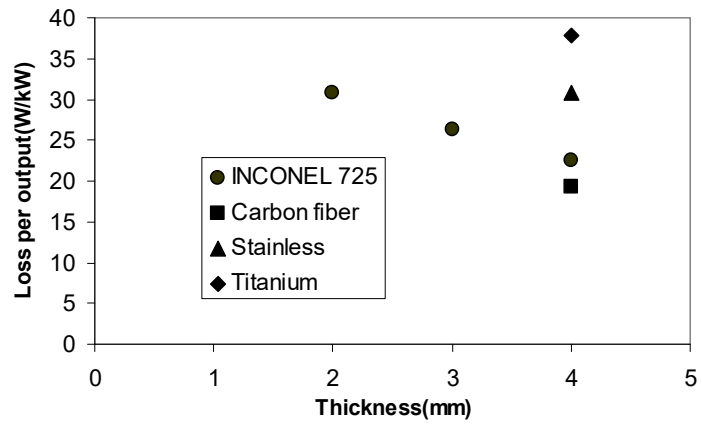

(b)

Fig. 4. Loss performance of machine with different sleeves. Prototype of the developed machine and stator end-cap. (a) Eddy loss in sleeve, (b) Loss per output.

\section{B. Eddy current loss in magnets}

To estimate the eddy loss in magnet blocks, 3-D FEA in machine with different magnet blocks are carried out. In the investigation, half of machine in axial direction is considered in the model, which includes the end windings, and so as the end flux leakage effects are involved in the calculation. The details of the model used in the 3-D FEA are shown in Fig 5.

Fig 6 shows the obtained eddy current density distribution. The 3-D FEA has of similar results have a regularly flux distribution, and only some saturated magnetic density, about $3 \mathrm{~T}$, appears in the elements in stator tooth top. Consequently, the obtained core loss is very close to that from 2-D analyses with a difference of $2.5 \%$.

For magnet eddy loss, a small manufacture gap about 0.02 $\mathrm{mm}$ around each magnet blocks, to simulate the glue layer between two magnets and make sure the investigation, is 
built. The 3-D eddy current vector figure shows that this eddy current are circling within one magnet block, and the peak value of eddy current is about $9.6 \mathrm{~A} / \mathrm{m}^{2}$. For magnets, the eddy current distributions are different according with its location. For the block at the corner of a pole, its peak eddy current density is only $1.7 \mathrm{~A} / \mathrm{m}^{2}$, so its eddy loss will be surely smaller. Compare with the magnet blocks eddy loss obtained from 2-D analyses, its eddy loss reduced about $25 \%$ with a designed splited blocks pole, which has of 6X6 blocks in one original entire magnet. Considering the manufacture arts, the magnet blocks should be reasonably divided into 4-6 segments in axial direction. And also the costs, the reliability, and strength, etc. are should considered further.

Based on the proposed magnet topology, other three different designs. Case I the magnet block is splited into 9X9 pieces. Case II the magnet laminated as $3 \mathrm{~mm}$, and Case III laminated into $0.7 \mathrm{~mm}$. Just as shown in Fig. 7.

The eddy loss in magnet with different topologies are list in Table III. From the 3-D FEA, the splited magnet blocks design could reduce its loss up to $89 \%$. For the laminated magnets, the losses in magnet with thickness of $3 \mathrm{~mm}$ and $0.7 \mathrm{~mm}$ are quite close. The difference between Case II and Case III should be caused by calculating error. Considering the coast and manufacture, the laminated magnet with $3 \mathrm{~mm}$ is proper.

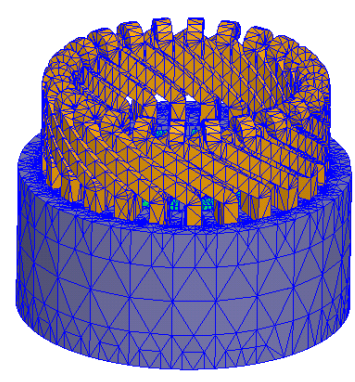

(a)

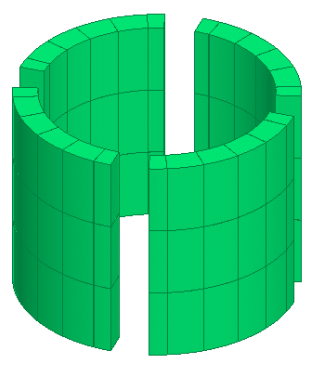

(b)
Fig. 5. 3-D FEA model for magnet eddy field investigation. (a) Elements in calculation model, (b) Separated magnet blocks.

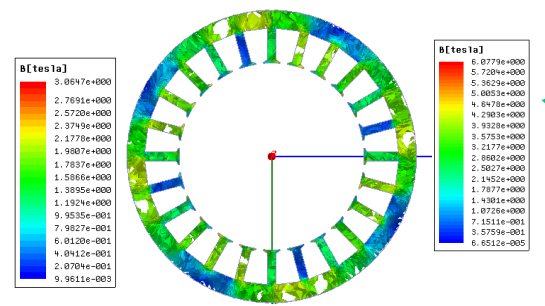

(a)
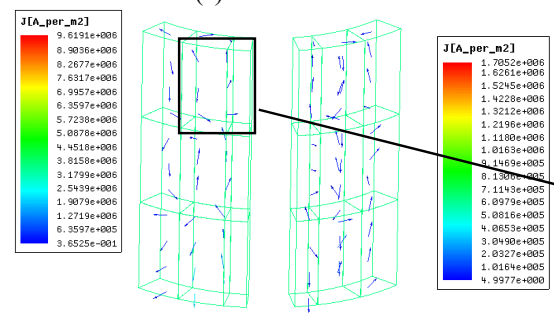

(c)

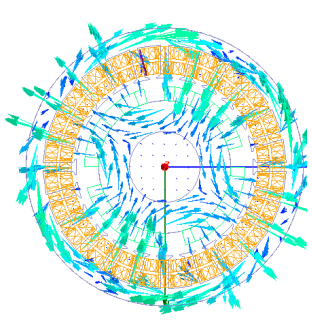

(b)

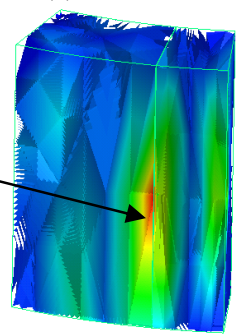

(d)
Fig. 6. 3-D FEA results in magnets. (a) Magnetic density in stator core. (b) Flux distribution in machine (z-axial view). (c) Eddy current vector in magnet blocks. (d) Eddy current in magnets blocks.

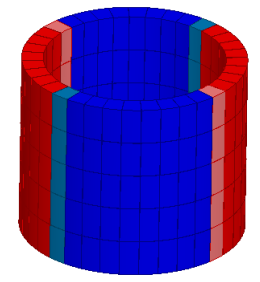

(a)

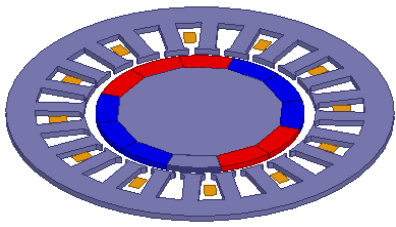

(b)

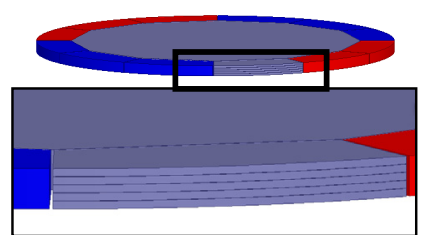

(c)
Fig. 7. New magnet topologies. (a) Case I. (b) Case II. (c) Case III.

TABLE III

MAIN PARAMETERS OF THE DEVELOPED HIGH SPEED PM STARTER GENERATOR

\begin{tabular}{lccccc}
\hline $\begin{array}{c}\text { Performance } \\
\text { / Machines }\end{array}$ & one block & 6 X6 & Case I & Case II & Case III \\
\hline $\begin{array}{l}\text { Eddy loss in } \\
\text { magnets/W }\end{array}$ & 308 & 234 & 173 & 32.29 & 34.22 \\
\hline
\end{tabular}

\section{Eddy current loss in end-cap edge}

By using the same 3-D FEA method, the eddy field and eddy current loss in end-cap edge is studied in this chapter. The end-cap is modelled according to the practical mechanical design of prototype, as shown in Fig. 8. For the housing part at the back iron/windings is comparatively far from the end windings, its eddy loss in this analysis is ignored. D1 is the distance between end-cap edge and rotor magnet outer surface. D2 is the distance from stator core to end-cap edge, as shown in Fig.8.

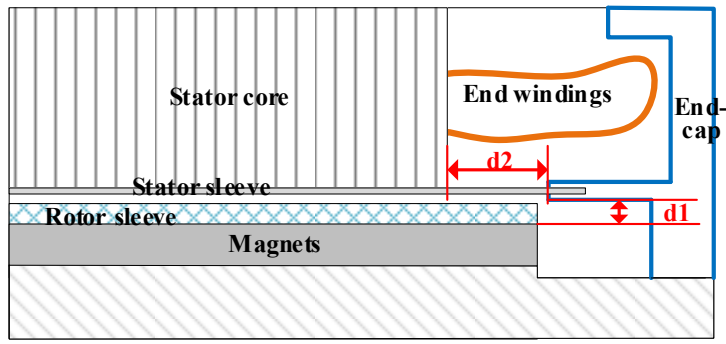

Fig. 8. The mechanical components in high speed PM starter generator.

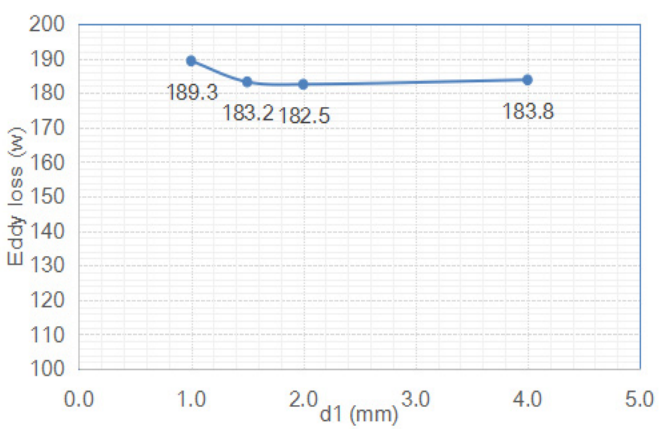

Fig. 9. Variation of eddy current loss in stator end cap as $\mathrm{d} 1$. 


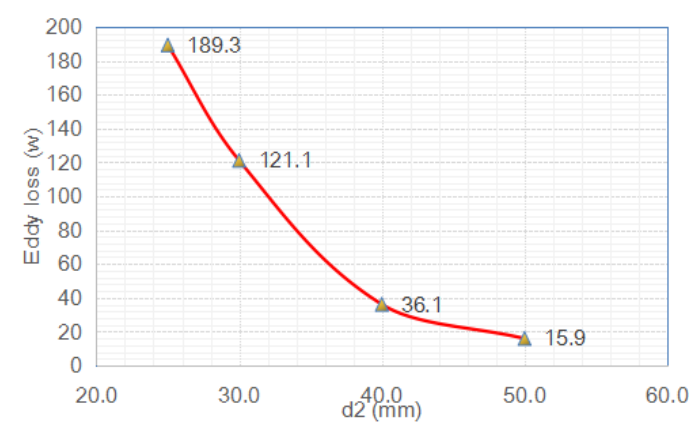

Fig. 10. Variation of eddy current loss in stator end cap as $\mathrm{d} 2$.

From the calcification, the eddy current in end-cap is nearly not changed as $\mathrm{d} 1$, but reduces obvious as $\mathrm{d} 2$ increase. It can be inferred that rotor magnet end flux leakage has rare effects on edge eddy loss. The stator end-cap edge should be $40 \mathrm{~mm}$ away from core ends.

\section{CONCLUSION}

This paper addresses the eddy loss current control in high speed PM starter-generator, via the 2-D 3-D combined electromagnetic FEA. In the view of eddy current loss, carbon fiber could be used as the rotor restrain sleeve, but the working temperature restriction of glue should be considered. Laminated magnet could reduce eddy loss in magnet up to $88 \%$ but with a higher cost and manufacture arts requests. To reduce the eddy current loss in stator endcap, the edge should at least $40 \mathrm{~mm}$ away from machine stator core end surface.

\section{REFERENCES}

[1] Z. A. Needell, J. McNerney, M. T. Chang and J. E. Trancik, "Potential for widespread electrification of personal vehicle travel in the United States," Nature Energy, vol. 1, no. 16112, Aug. 2016

[2] Directorate-General for Mobility and Transport, "Flightpath 2050 Europe's Vision for Aviation," Report of the High Level Group on Aviation Research, EU Commission, [Online]. Available: https://ec.europa.eu/transport/sites/transport/files/modes/air/doc/flightp ath2050.pdf.

[3] E. Bertolini, S. Eure, P. Hecker, M. Huguet and F. Sanna-Randaccio, "Clean Sky 2 Impact Assessment," Final Report of the Expert Group of the Clean Sky 2 governing board, 2012, [Online]. Available: https://www.cleansky.eu/sites/default/files/documents/admin/2012092 9-panel-report-impact.pdf
[4] M. A. Rahman, A. Chiba, T. Fukao, "Super high speed electrical machines-summary," in Proc. Power Engineering Society General Meeting, vol. 2, pp. 1272-1275, 6-10 Jun. 2004, Denver, CO, USA.

[5] D. Gerada, A. Mebarki, N. L. Brown, C. Gerada, A. Cavagnino, M. Galea, A. Boglietti, "High-Speed Electrical Machines: Technologies, Trends, and Developments," IEEE Trans. Ind. Electron., vol. 61, pp. 2946-2959, Jun. 2014.

[6] Z. Zhang, J. Huang, Y. Jiang, W. Geng, Y. Xu, "Overview and Analysis of PM Starter/Generator for Aircraft Electrical Power Systems," CES Trans. Electrical Machines. System. vol. 1, no. 2, pp. 117-131, Jun. 2017.

[7] D. Papaoikonomou, M. van der Geest, H. Polinder, "Comparison between induction and PM machine for high speed startergeneratorapplications," in Proc. IET Intel. Conf. Power Electronics, Machines and Drives (PEMD 2014), pp. 1-6, 8-10 Apr. 2014, Manchester, UK.

[8] F. Liu, L. Xu, Y. Li, Y. Kang, Z. Wu, "Permanent magnet synchronous machine starter/generators based high-voltage DC parallel electric power system for the more electric aircraft," The Journal of Engineering, vol. 2018, no, 13, pp. 565-569, Aug. 2018.

[9] P. D. Pfister, Y. Perriard, "Very-High-Speed Slotless PermanentMagnet Motors: Analytical Modeling, Optimization, Design, and Torque Measurement Methods," IEEE Trans. Ind. Electron., vol. 57, vo. 1, pp. 296-303, Jul. 2009.

[10] F. R. Ismagilov, V. E. Vavilov, D. V. Gusakov, "High-Speed StarterGenerator for Aerospace Applications: Design and Initial Testing," in Proc. XIII International Conference on Electrical Machines (ICEM), pp. 2593- 2599, 3-6 Sep. 2018, Alexandroupoli, Greece.

[11] A. Chebak, P. Viarouge, J. Cros, "Analytical Computation of the Full Load Magnetic Losses in the Soft Magnetic Composite Stator of HighSpeed Slotless Permanent Magnet Machines," IEEE Trans. Mag., vol. 45, no. 3, pp. 952-955, Feb. 2009

[12] X. Zhang, W. Li, C. Gerada, H. Zhang, et.al. "CQICO and multiobjective thermal optimization for high speed PM generator," IEEE Trans. Mags, vol. 53, no. 6, 8201604, Jun. 2017.

[13] A. Krings, M. Cossale, A. Tenconi, J. Soulard, et.al. "Magnetic Materials Used in Electrical Machines: A Comparison and Select ion Guide for Early Machine Design". IEEE Ind. App. Mag., vol. 53, no. 1, pp. 21-28, Nov/Dec. 2017.

[14] J. Zhu, Y. Guo, Z. Lin, et al. "Development of PM transverse flux motors with soft magnetic composite cores". IEEE Trans. Mags., vol. 47, no. 10, pp. 4376-4383, Sep. 2011.

[15] X. Zhang, W. Li, B. Kou, et al. "Electro-thermal combined optimization on notch in air cooled High Speed Permanent Magnetic Generator," IEEE Trans. Mags., vol. 51, no. 1, \# 8200210, Jun. 2014.

[16] J. B. Bartolo, M. Degano, J. Espina, C. Gerada, "Design and Initial Testing of a High-Speed $45-\mathrm{kW}$ Switched Reluctance Drive for Aerospace Application," IEEE Trans. Ind. Electron., vol. 64, no. 2, pp. 988- 997, Feb. 2017.

[17] W. Li, X. Zhang, S. Cheng, and J. Cao, "Thermal Optimization for a HSPMG Used for Distributed Generation Systems," IEEE Trans. Ind. Electron., vol. 60, no. 2, pp. 474-482, Feb. 2013. 